\title{
Investigation on Cathodoluminescence Properties of Copper Implanted ZnO Samples
}

\author{
Yasemin Tuncer Arslanlar ${ }^{1 *}$, Illker Çetin Keskin ${ }^{1}$, Mehmet İsmail Katı ${ }^{2}$, Murat Türemişs ${ }^{3}$ Ahmet Çetin ${ }^{1}$, \\ Rana Kibar ${ }^{1}$
}

\author{
${ }^{1}$ Department of Physics, Faculty of Art and Science, Manisa Celal Bayar University, Manisa, Turkey \\ ${ }^{2}$ Experimental Science Applications and Research Center, Manisa Celal Bayar University, Manisa, Turkey \\ ${ }^{3}$ Faculty of Engineering and Natural Sciences, Department of Physics, Bursa Technical University, Bursa, Turkey \\ *tunceryasemin@hotmail.com
}

Received: 26 October 2018

Accepted: 24 June 2019

DOI: $10.18466 /$ cbayarfbe. 475150

\begin{abstract}
$\mathrm{ZnO}$ single crystals has been implanted with $400 \mathrm{keV} \mathrm{Cu}$ ions at fluences of $2,5 \times 10^{16}$ ions $/ \mathrm{cm}^{2}$ at room temperature. The cathodoluminescence (CL) measurements of pure and $\mathrm{Cu}$ implanted samples has been reported at UV-visible range at both room and different temperatures. After the implantation process, the samples were annealed for 1 hour at $1000^{\circ} \mathrm{C}$. The effects of ion implantation and annealing temperature and on the CL signals were researched with the data obtained. The CL spectrum of pure $\mathrm{ZnO}$ exhibited two emission bands at $385 \mathrm{~nm}$ and $550 \mathrm{~nm}$. There are some changes in the emission bands in the CL spectrum that are thought to be due to the presence of $\mathrm{Cu}$ ions. Also it is possible to say that the annealing temperature can strongly influence CL intensity.
\end{abstract}

Keywords: $\mathrm{ZnO}$, Ion Implantation, Nanoparticles, Cathodoluminescence.

\section{Introduction}

$\mathrm{ZnO}$ having wurtzite hexagonal crystal structure is a semi-conductor with high radiation resistance, $60 \mathrm{meV}$ exciton binding energy, and obtains $3.4 \mathrm{eV}$ energy bond range at room temperature $[1,2]$.

It has a wide range of application area including optoelectronic, piezoelectric devices, semiconductor detectors, LEDs, gas sensors and laser technology [3].

Cathodoluminescence is the light emitted by a specimen when bombarded with electrons. The electrons only penetrate a small distance (a few microns) into the sample and therefore, the method can only be used to study the surface region of the material. It offers a precise analysis of the surface region of insulating and semiconducting materials. As the wavelengths of radiation depend on the nature of the sample, it is possible to identify its chemical composition, defects, impurities and imperfections [4].

Characteristic and luminescence properties of many materials, that have a wide range of application area in the industry, may be changed by the ion implantation process. Ion implantation is made by inserting high velocity ions into the target and this process changes the surface properties of the material. Ion implanted samples are widely used for development of the photonic and optoelectronic devices. By this method, different type and structured crystals can be obtained $[5,6]$.
In this study, the ion dose was increased as much as possible and the sample was annealed. In addition, CL measurements were taken between 300-40 K temperatures. In such spectroscopic methods, the change in crystal behavior with lower temperatures leads to significant alterations in the emission band obtained. The formation of metal nanoparticles by implantation of $\mathrm{Cu}$ ions to the $\mathrm{ZnO}$ single crystal and the variation of the cathodoluminescence properties in relation to this process has been investigated. There are some differences in relative peak positions and intensities between pure and implanted samples. The $\mathrm{CL}$ spectra of $\mathrm{Cu}$ implanted $\mathrm{ZnO}$ were also taken following furnace annealing at $1000{ }^{\circ} \mathrm{C}$ at 1 hour in air.

\section{Materials and Methods}

The polished wurtzite $\mathrm{ZnO}$ single crystals $10 \times 5 \times 0.4$ $\mathrm{mm}^{3}$ purchased from MATECK, Germany. The samples were implanted with $\mathrm{Cu}$ ions at room temperature in a vacuum of $10^{-6}$ mbar at energy of 400 $\mathrm{keV}$ at fluence of $2,5 \mathrm{x} 10^{16} \mathrm{ions} / \mathrm{cm}^{2}$ on an EATON 3204 implanter in Juelich in Germany on a ZnO crystal surface layer. After implantation process, the samples were annealed at $1000{ }^{\circ} \mathrm{C}$ using a Proterm tube furnace in air.

After these processes, the surface morphology of the crystal has been investigated by Shimadzu SPM-9500 AFM in İTÜ Physics Department. The surface photos 
of the samples were taken at room temperature. The CL spectrums at different temperatures between room temperature and $40{ }^{\circ} \mathrm{K}$ has been taken at also $250-825$ $\mathrm{nm}$ wavelengths under DC electron beam excitation.

The data collected are for an accelerating potential of $10-24 \mathrm{keV}$ and a current of $20 \mathrm{nA}$, which corresponds to an incident power density of $0.8 \mathrm{mWcm}^{-2}$. The light from the sample was focused via a quartz lens, onto the entrance slit of a grating monochromator with $\mathrm{f} / 4$ light collection and detected by a blue-sensitive photomultiplier tube (PMT, EMI 9813Q). The quantum efficiency of EMI 9813Q is between $15 \%$ and $25 \%$ in the range of $200 \mathrm{~nm}$ to $600 \mathrm{~nm}$.

\section{Results and Discussion}

In Figure 1a, the present impurity atoms in pure $\mathrm{ZnO}$ could be seen. After the ion implantation, the atoms join the target. By this process, the surface roughnesses occur. In the photos taken after annealing process, it is clearly seen that the ion clusters expanded.
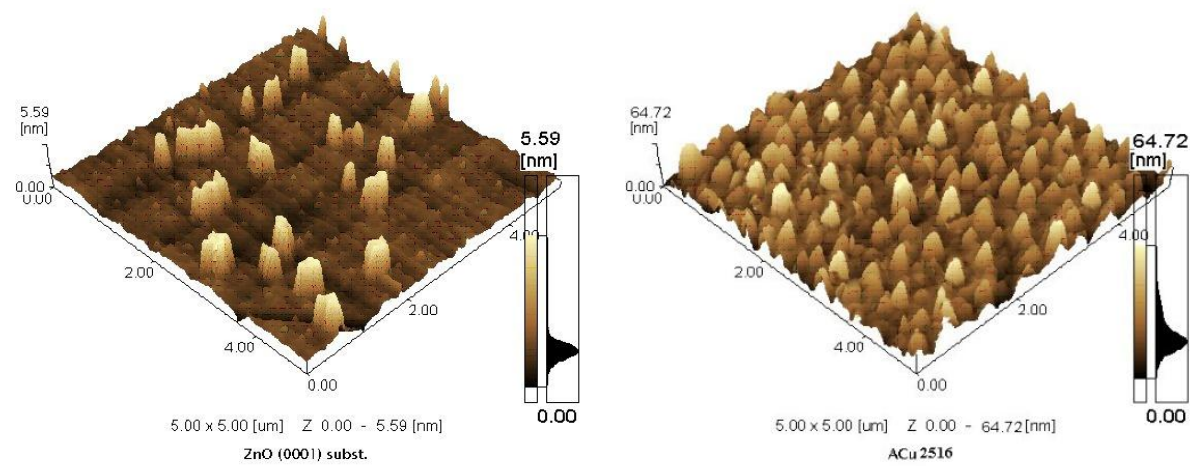

a)

b)

Figure 1. a) The AFM photo of single $\mathrm{ZnO}(0001)$ crystal b) The AFM photo of $\mathrm{ZnO}: \mathrm{Cu} 2.5 \times 10^{16}$ ions $/ \mathrm{cm}^{2}$ sample after 1 hour annealing process.

It is known that, generally $\mathrm{ZnO}$ has a few luminescence band in the UV and visible region. The UV band is related to excitonic transitions, either free or bound, and their phonon replicas, and eventually some donor acceptor pair transitions. The visible luminescence due

to recombination in deep levels is related to either impurities or native defects $[7,8]$. These defects play very important roles in the optical properties of materials.

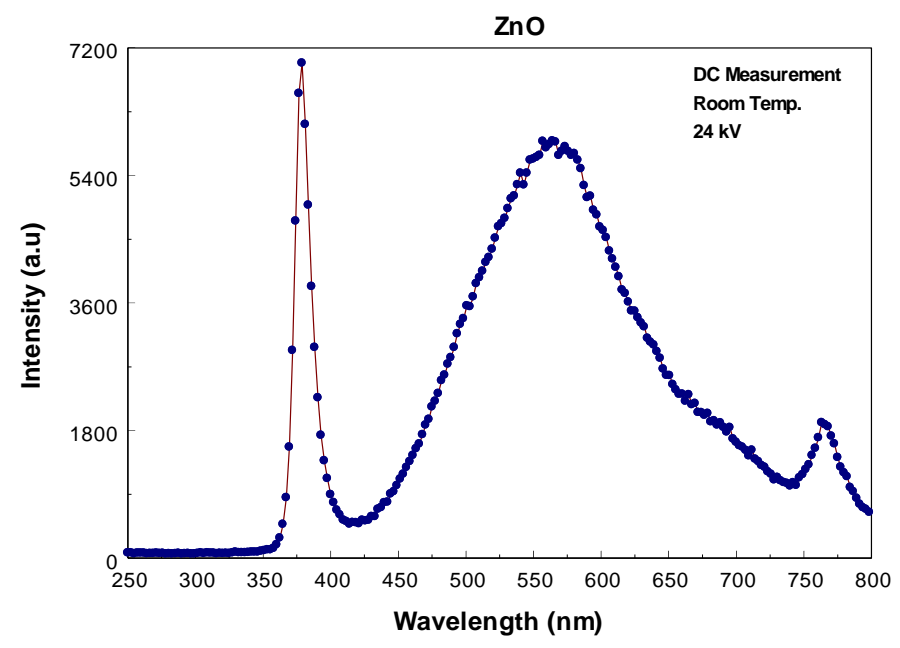

Figure 2. The CL spectrum of pure $\mathrm{ZnO}$ at room temperature.

It can be seen that variation of the emission spectrum when pure $\mathrm{ZnO}$ single crystal is bombarded with $24 \mathrm{kV}$ electron beam (Fig.2). The luminescence spectrum of $\mathrm{ZnO}$ exhibit two luminescence bands a shortwavelength band (the edge luminescence), which is located near the absorption edge of the crystal, and a broad long-wavelength band, the maximum of which usually is in the green spectral range There is a sharp peak at $385 \mathrm{~nm}$ with a maximum. This peak corresponds to UV radiation. The edge luminescence at $385 \mathrm{~nm}$ associated with exciton and exciton-like states is observed in the near-UV spectral range. The wide 
emission band between 400-700 nm obtains maximum at $550 \mathrm{~nm}$. This band shows that $\mathrm{ZnO}$ is a material that emits green light. The luminescence centers that are zinc vacancies $\left(\mathrm{V}_{\mathrm{Zn}}\right)$, oxygen vacancies $\left(\mathrm{V}_{\mathrm{O}}\right)$, interstitial zinc ions $\left(\mathrm{Z}_{\mathrm{ni}}\right)$ and transitions $\mathrm{Z}_{\mathrm{ni}}-\mathrm{V}_{\mathrm{Zn}}$ were assumed to be responsible for the green luminescence. These results are compatible with the literature $[9,10]$.

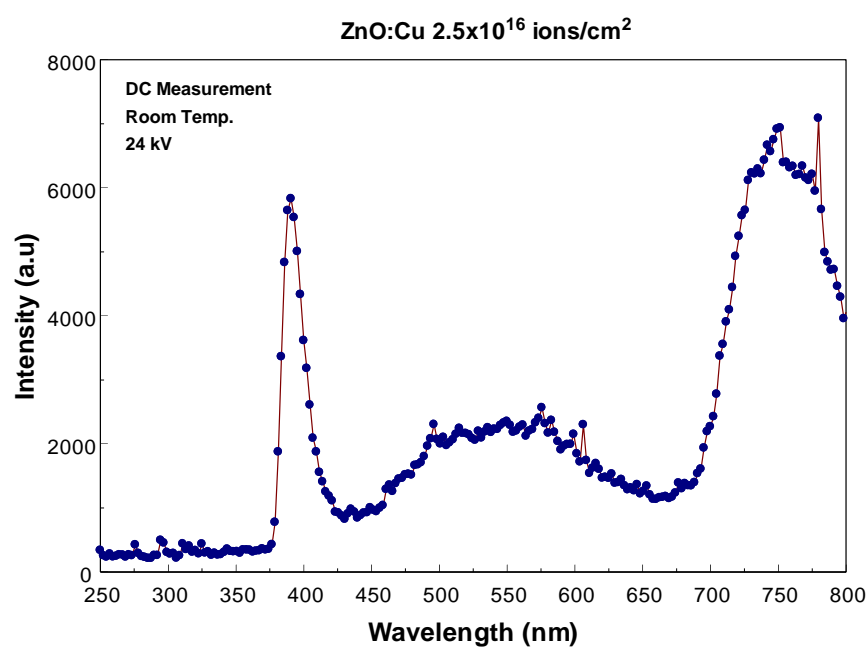

Figure 3. $\mathrm{CL}$ spectrum of $\mathrm{Cu}$ implanted $\mathrm{ZnO}$ with concentration $2.5 \times 10^{16}$ ions $/ \mathrm{cm}^{2}$ when bombarded with $24 \mathrm{kV}$ electron beam.

In Figure 3, the effect of the ion implantation to the CL intension can be seen. The intension of the peak at 385 $\mathrm{nm}$ is rationally decreases. The peak originated from ion implantation and electron vacancy couples. This situation is thought to be originated from the bonding of the ions with the bombarded electron vacancy couples. After $\mathrm{Cu}$ bombardment, the wide emission band at $550 \mathrm{~nm}$ loses its strength. It is thought that the $\mathrm{Cu}$ atoms bonded to the oxygen atoms and create metallic structure and because of this structure, $\mathrm{Cu}$ ions and oxygen vacancies loses contribution to radiation.

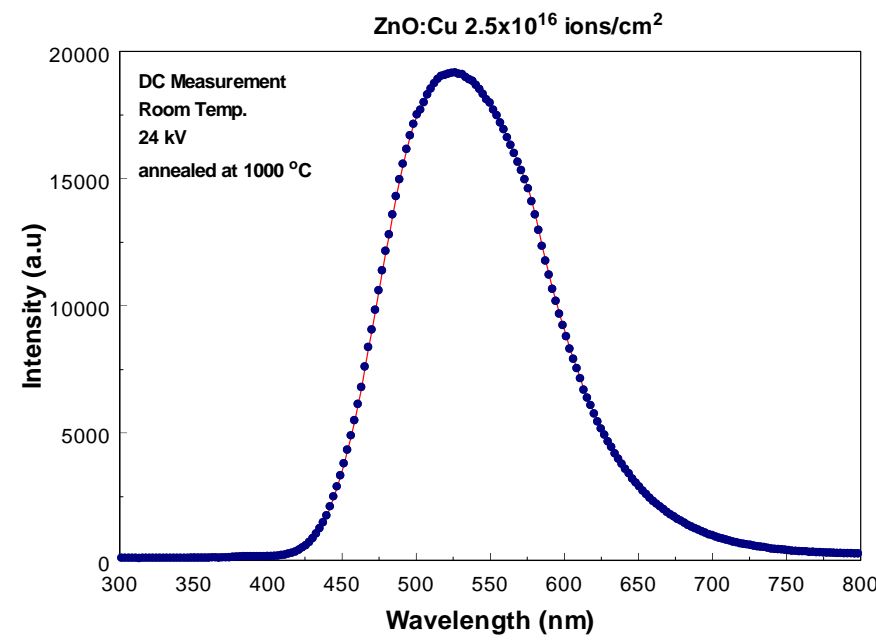

Figure 4. $\mathrm{CL}$ spectra of $\mathrm{ZnO}$ with $2.5 \times 10^{16}$ ions $/ \mathrm{cm}^{2} \mathrm{Cu}$ ions implanted and annealed in air.

In Figure 4, the recorded CL spectrum of the $\mathrm{ZnO}$ sample after implanted with $\mathrm{Cu}$ and one hour annealing at $1000^{\circ} \mathrm{C}$ can be seen. The intensity of the visible emission increased approximately 3 times according to pure $\mathrm{ZnO}$ after annealing. This situation is related with the increment of the diameter of atom clusters that affected by the implantation and annealing processes. Furthermore, both the oxygen in metallic structure that is thought to be formed by implantation and the burning of free oxygen during annealing copper ions are revealed. Revealed $\mathrm{Cu}$ ions have a big importance in the increment of the intensity of the peak [11]. 


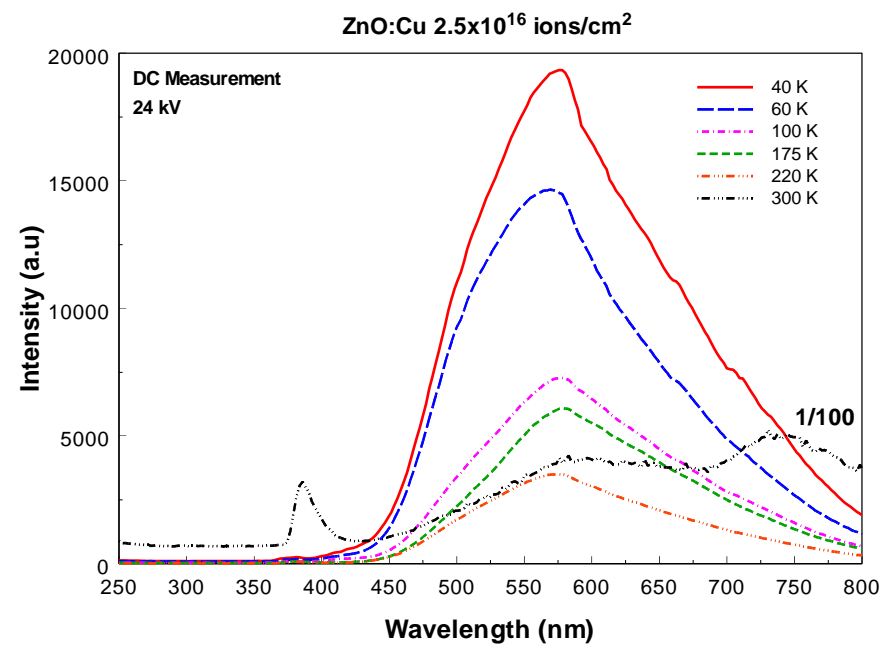

Figure 5. The DC CL spectra of the $\mathrm{Cu}$ implanted $\mathrm{ZnO}$ at $2.5 \times 10^{16}$ ions $/ \mathrm{cm}^{2}$ dose crystal at different temperatures.

In Figure 5, DC CL spectrums at selected temperatures can be seen during heating from $40 \mathrm{~K}$ to room temperature. Luminescence signals were found to be strongly affected by temperature. As can be seen in the $\mathrm{CL}$ spectrum of the $\mathrm{Cu}$ implanted $\mathrm{ZnO}$ sample, the intensity of the sharp peak at about $390 \mathrm{~nm}$ resulting from excitons was influenced by the temperaturedependent behavior of electron-hole pairs. This effect can be clearly seen in Figure 5. The UV emission present at room temperature disappeared at $40 \mathrm{~K}$. However, the visible emission intensity increases significantly as the temperature decreases. One of the reasons for this increase is the substantial elimination of non-radiative transitions.

\section{Conclusion}

$\mathrm{Cu}$ implanted samples differ from pure $\mathrm{ZnO}$ in terms of defect structure and the luminescence properties of the material has changed. There are some differences in relative peak positions and intensities between pure and implanted samples. The UV and visible emission of $\mathrm{ZnO}$ is widely used especially in LED technology. The visible emission intensity significantly increased by the implantation and annealing processes. However, different dosage usages for $\mathrm{ZnO}$ samples can also be investigated in order to find out the effects on luminescence efficiency.

\section{Author's Contributions}

Yasemin Tuncer Arslanlar: Drafted and wrote the manuscript, performed the experiment and result analysis.

İker Çetin Keskin: Assisted in analytical analysis helped in manuscript preparation.

Mehmet İsmail Katı: Wrote the interpretation of AFM.

Murat Türemiş: Performed the experiment and result analysis and drawed
Ahmet Çetin: Supervised the experiment's progress, result interpretation and helped in manuscript preparation.

Rana Kibar: Supervised the experiment's progress, result interpretation and helped in manuscript preparation.

\section{Ethics}

There are no ethical issues after the publication of this manuscript.

\section{References}

1. Jadwisienczak,W. M, Lozykowski, H. J, Xu, A, Patel, B. 2002. Visible emission from $\mathrm{ZnO}$ doped with rare-earth ions. Journal of Electronic Materials; 31(7) 776-784.

2. Coskun, C, Look, D C, Farlow, G C, Sizelove, J R. 2004. Radiation hardness of $\mathrm{ZnO}$ at low temperatures. Semiconductor Science and Technology; 19(6) 752-754.

3. Jagadish, S, Pearton, S, 2006. Zinc Oxide Bulk, Thin Films and Nanostructures; Australian National Univ. Australia.

4. Karali, T, Can, N, Valberg, L, Stephanov, A.L, Townsend, P.D, Buchal, C.H, Ganeev,R.A Ryasnyanskya, A.L, Belik, H.G, Jessett, M.L, Ong, C, 2005. Physica B: Considered Matter; 363(1-4) 88-95

5. Kibar, R, Farklı Metal İyonları ile bombalanan $\mathrm{SrTiO}_{3}$ Kristalinin ve Bazı Minerallerin Nükleer ve diğer Yöntemlerle İncelenmesi Ege Üniv. Fen Bilimleri Enstitüsü, İzmir 2007; pp

6. Bird, J.R, Williams, J.S, Ion Beams for Materials analaysis Acedemic Press: Australlia, 1989.

7. Sanjeev, S, Kekuda, D, Effect of Annealing Temperature on the Structural and Optical Properties of Zinc Oxide $(\mathrm{ZnO})$ Thin Films Prepared by Spin Coating Process; ICMST 2012(2015); 7301214.

8. TsungHsieh, $\mathrm{P}$, ShanChin, H, KuanChang, $\mathrm{P}$, MingWang, C, ChungChen, Y, PhonHoung, M. 2010. Effects of the annealing environment on green luminescence of $\mathrm{ZnO}$ thin films. ,Physica B: Condensed Matter; 405(11): 2526-2529. 
Celal Bayar University Journal of Science

Volume 15, Issue 2, 2019, p 145-149

Doi: $10.18466 /$ cbayarfbe. 475150

Y. Tuncer Arslanlar

9. Rodnyi, P.A and Khodyuk, I.V. 2011. Optical and Luminescence Properties of Zinc Oxides. Optics and Spectroscopy; 111(5): 776-786.

10. Rodnyi, P.A, Chernenko, K.A, Venevtsev I.D. 2018 Mechanisms of $\mathrm{ZnO}$ Luminescence in the visible Spectra Region. Spectroscopy of Considered States; 125(3): 357-363.
11. Çetin, A, Farklı Metalik İyonlarla Bombalanan $\mathrm{ZnO}$ Örneklerinin Fiziksel ve Yapısal Özelliklerinin Nükleer,Lüminesans ve Diğer Teknikler Kullanılarak İncelenmesi. Ege Üniversitesi Fen Bilimleri Enstitüsü, 2007. 